\title{
PROPOSTA DE IMPLEMENTAÇÃO DE UM PROGRAMA DE FIDELIZAÇÃO EM UMA OPERADORA DE CINEMAS: ESTUDO DE CASO NA CINÉPOLIS EM MANAUS
}

\section{ARTIGO ORIGINAL}

SANTOS, Ana Luiza Pires dos ${ }^{1}$, LEITE, Victor Gabriel Almeida ${ }^{2}$, AQUINO, Gustavo Castro de ${ }^{3}$, ROBERTO, José Carlos Alves ${ }^{4}$, ALMEIDA, Victor da Silva $^{5}$

SANTOS, Ana Luiza Pires dos. Et al. Proposta de implementação de um programa de fidelização em uma operadora de cinemas: Estudo de caso na Cinépolis em Manaus. Revista Científica Multidisciplinar Núcleo do Conhecimento. Ano. 06, Ed. 10, Vol. 06, pp. 45-65. Outubro 2021. ISSN: 2448-0959, Link de acesso: https://www.nucleodoconhecimento.com.br/administracao/programa-de-fidelizacao, DOI: 10.32749/nucleodoconhecimento.com.br/administracao/programa-defidelizacao

\section{RESUMO}

A finalidade deste artigo é descrever a proposta de implementação de um programa de fidelização na empresa Cinépolis visando o alcance de novos clientes e a preservação do relacionamento. Diagnosticou-se através de estudo feito na organização que a sua área mais crítica é a do marketing em virtude da inexistência de estratégias voltadas para esta, principalmente com realização a falta de vantagens oferecidas ao cliente no que tange fidelização e do uso ineficiente das ferramentas digitais. Com base nisso, definiu-se a pergunta problema "como a implementação do marketing de relacionamento pode coadjuvar na fidelização de

\footnotetext{
${ }^{1}$ Graduanda do curso de Administração.

${ }^{2}$ Graduando do curso de Administração.

${ }^{3}$ Graduando do curso de Administração.

${ }^{4}$ Orientador. Mestre em Engenharia de produção. Especialista Logística empresarial. Graduado em Administração com Ênfase em Marketing.

${ }^{5}$ Coorientador. Mestre em Engenharia de Processos. Pós-Graduando em Neuropsicopedagogia Institucional. Especialista em Gestão Estratégica de RH. Graduado em Administração e Pedagogia.
}

RC: 99341

Disponível em: https://www.nucleodoconhecimento.com.br/administracao/programade-fidelizacao 
clientes e no alcance de outros novos?" O objetivo geral desta pesquisa é demonstrar os benefícios da implementação de ações fundamentadas no marketing de relacionamento com o propósito de atrair e fidelizar clientes na empresa. A metodologia, quanto à natureza, é uma pesquisa aplicada com abordagem qualiquantitativa, quanto aos fins, é exploratória e descritiva, quanto aos meios, é bibliográfica. Fundamentadas nos princípios do CRM, no marketing de relacionamento e com o auxílio da ferramenta $5 \mathrm{~W} 2 \mathrm{H}$, as seguintes propostas de implementação foram definidas: reformular o atual plano de fidelização da empresa; criar benefícios exclusivos para membros do novo clube; executar a divulgação do clube de fidelização; e reestruturar o aplicativo da empresa.

Palavras-chave: Marketing, fidelização, ferramentas digitais.

\section{INTRODUÇÃO}

O presente artigo trata do estudo de caso realizado na operadora de cinemas Cinépolis, desenvolvido com o intuito de identificar possíveis pontos fracos na empresa, investigar e analisar os prováveis motivos para, posteriormente, propor soluções exequíveis. A partir do estudo feito, o marketing foi considerado a área mais crítica da organização, possuindo como pontos mais inconsistentes: a ausência do uso de estratégias de marketing nos processos da empresa; a falta de vantagens oferecidas aos clientes visando a fidelização; e o uso ineficiente dos canais digitais da organização.

De acordo com Carvalho et al. (2019), o problema de uma pesquisa gera um questionamento no qual o valor científico será mensurado com base no que se intenciona identificar ou resolver através da pergunta problema, determinando também os limites de investigação da pesquisa. Em vista disso, levando em conta as adversidades identificadas na área do marketing, estabeleceu-se a seguinte pergunta problema: "como a implementação do marketing de relacionamento pode coadjuvar na fidelização de clientes e no alcance de outros novos?". Foi a partir da 
questão norteadora que os objetivos gerais e específicos foram estabelecidos para alicerçarem o prosseguimento da pesquisa.

O objetivo geral deste trabalho é demonstrar os benefícios da implementação de ações fundamentadas no marketing de relacionamento objetivando atrair e fidelizar clientes na empresa Cinépolis do shopping Ponta Negra, em conformidade com os objetivos específicos que são: apresentar a importância de possuir um bom relacionamento cliente-empresa; evidenciar a atual essencialidade e proveitos do uso de ferramentas digitais para a organização; e retratar as vantagens da instalação de um novo plano de fidelização na empresa.

Por intermédio das pesquisas e estudos efetuados na organização, e utilizando-se dos preceitos do marketing de relacionamento, do marketing digital, do CRM e da ferramenta $5 \mathrm{~W} 2 \mathrm{H}$, serão apresentadas neste artigo, tendo em vista a solução das adversidades identificadas na área do marketing, as seguintes propostas: a reformulação do atual plano de fidelização da empresa; a criação de benefícios exclusivos para membros do novo clube; o uso eficiente das ferramentas digitais para executar a divulgação do clube de fidelização; e a reestruturação do aplicativo da empresa.

Espera-se que através deste estudo e da aplicação das propostas de solução apresentadas neste artigo, a organização possa erradicar os principais gargalos contidos no marketing para que, consequentemente, obtenha benefícios através da captação e fidelização de clientes.

\section{FUNDAMENTAÇÃO TEÓRICA}

A fundamentação teórica possui a finalidade de embasar a pesquisa pois se trata da abordagem de diversos estudos de outros autores que podem ser utilizados para complementar o trabalho e contribuir com o entendimento do tema, servindo também como orientação para o estudo e avaliação de determinados dados.

RC: 99341

Disponível em: https://www.nucleodoconhecimento.com.br/administracao/programade-fidelizacao 
O propósito da criação da fundamentação teórica é propagar os materiais e estudos de outros autores que abordam o mesmo tema. Isso possibilita a exposição de conteúdos e conceitos que se complementam e embasam a pesquisa bibliográfica (ZANELLA, 2013).

A pesquisa bibliográfica é desenvolvida baseada em materiais que já foram publicados. Comumente, esse processo é fundamentado com livros, revistas, dissertações ou artigos (GIL, 2017).

\subsubsection{CONCEITO DE MARKETING}

Constata-se que o marketing tem como finalidade a compreensão do mercado-alvo escolhido pela organização para identificar as suas necessidades e supri-las através da geração de valor sobre produtos, serviços ou a própria empresa, visando atrair e fidelizar clientes para desenvolver um relacionamento vantajoso para ambas as partes.

O marketing compreende a constatação e o atendimento das necessidades dos consumidores para satisfazê-los. A definição mais precisa de marketing é obter lucro suprindo necessidades (KOTLER E KELLER, 2018).

De acordo com a American Marketing Association, o marketing pode ser definido como uma função da organização e uma série de procedimentos que abrangem a elaboração, divulgação e concessão de valor aos clientes, assim como a manutenção do relacionamento existente entre eles e a empresa, visando beneficiar ambos (BARCELLOS E SCHELELA, 2012).

\subsubsection{CAPTAÇÃO E FIDELIZAÇÃO DE CLIENTES}

Para uma organização que deseja expandir, se manter lucrativa e se tornar referência no mercado, o processo de fidelização de clientes se torna tão importante quanto captar outros novos. Isso se dá por conta das vantagens de reter um consumidor, essa estratégia gira em torno da confiança entre o cliente e a empresa

RC: 99341

Disponível em: https://www.nucleodoconhecimento.com.br/administracao/programade-fidelizacao 
e exige a adoção constante de métodos que aprimorem e reforcem este relacionamento.

O processo de criação da fidelidade dos consumidores é longo, indo desde o desenvolvimento da estratégia para atrair o cliente para, consequentemente, despertar a curiosidade, garantir o vínculo e por fim, estabelecer a afinidade (KOTLER; KARTAJAYA E SETIAWAN, 2017).

Através da criação de valor, a empresa pode captar novos clientes e cultivá-los. Esse tipo de marketing inicia-se por meio da compreensão das necessidades e preferências do consumidor, a escolha do mercado-alvo que a empresa pretende atender e a construção de uma oferta com valor agregado para atrair clientes e preservá-los. Caso a empresa efetue esse processo da melhor forma, o retorno virá por meio da participação no mercado, dos rendimentos e customer equity (KOTLER E ARMSTRONG, 2015).

Um consumidor satisfeito sempre irá voltar a fazer negócios pois já reconhece a qualidade do produto, se sente seguro e conhece a marca, dessa forma, não precisa ser convencido a comprar novamente. Ademais, o cliente passa a indicar espontaneamente a marca com recomendações naturais e sinceras, assim como o seu feedback, onde o cliente fidelizado é honesto em suas avaliações e opiniões, visando sempre o aprimoramento dos serviços da empresa.

\subsubsection{MARKETING DE RELACIONAMENTO}

O marketing de relacionamento é uma estratégia que visa, além de propagar a marca e conquistar novos consumidores, fidelizar o cliente, criando um vínculo de proximidade entre consumidor e empresa. A construção desse relacionamento ocorre por intermédio da criação de valor, contexto em que a empresa oferece vantagens que cultivam o cliente, satisfazendo-o em suas necessidades e indo além das expectativas geradas. Desta forma, a empresa conquista verdadeiros fãs, dispostos a disseminar e a defender a marca.

RC: 99341

Disponível em: https://www.nucleodoconhecimento.com.br/administracao/programade-fidelizacao 
O desenvolvimento de relacionamentos sólidos com qualquer pessoa ou empresa que possa, seja de maneira direta ou indireta, interferir no bom desempenho da empresa, é um dos objetivos fundamentais do marketing. O propósito do marketing de relacionamento é criar vínculos duradouros e benéficos para ambas as partes envolvidas (KOTLER E KELLER, 2018).

O relacionamento com o cliente e a criação de valor são fatores imprescindíveis nos dias atuais onde os consumidores estão gastando de forma cada vez mais prudente. Saber criar valor e administrar o relacionamento com as pessoas, encantando-as e superando as suas expectativas, fazem com que as empresas conquistem o valor dos clientes, obtenham mais lucros e a fidelidade. Consumidores satisfeitos possuem uma tendência maior para serem fiéis com a empresa (KOTLER $E$ ARMSTRONG, 2015).

\subsubsection{MARKETING DIGITAL}

De acordo com Oliveira (2018), o marketing digital é uma nova forma de explorar o ambiente digital tendo como meta intensificar o relacionamento da empresa com o cliente e aumentar a venda de seus produtos e serviços.

Observando o cenário atual, é possível perceber como é interessante para uma organização investir fortemente nesse meio de divulgação, procurando sempre formas criativas de atrair e manter o público desejado. Sendo assim, a marca ganha mais visibilidade e atrai um grupo de pessoas que irá divulgar suas experiências e influenciar amigos e conhecidos a comprarem o mesmo produto através de suas redes sociais, isentando a empresa de gastar qualquer valor pela divulgação.

Como é apontado por Kotler; Kartajaya e Setiawan (2017), por meio da visão da comunicação de marketing, é possível perceber hoje em dia que os clientes não são apenas alvos passivos, mas também, são uma forma de mídia ativa de comunicação.

RC: 99341

Disponível em: https://www.nucleodoconhecimento.com.br/administracao/programade-fidelizacao 
Dessa forma, a empresa deve sempre considerar que o consumidor não apenas comprará um produto ou usufruirá de um serviço, mas também divulgará digitalmente as suas avaliações e opiniões, influenciando outras pessoas a comprarem e a experimentarem o que empresa tem a oferecer, atestando por si próprias a qualidade do produto ou serviço.

Atualmente essa nova modalidade de marketing se tornou uma das melhores estratégias para as companhias divulgarem suas marcas e produtos com facilidade, atraindo assim, novos clientes e mantendo uma boa comunicação com eles.

\subsubsection{BENEFÍCIOS DO APLICATIVO PARA UMA EMPRESA}

É nítido como os hábitos dos consumidores têm mudado com a expansão da internet no mundo todo. Hoje em dia, os clientes estão sempre comprando ou acessando serviços pelo celular sem precisar sair de casa por conta da praticidade e do conforto. Por esse motivo, aplicativos se tornaram indispensáveis para empresas que querem atrair e fidelizar seus clientes.

Silva e Santos (2014) mostram que os aparelhos celulares hoje em dia sofreram uma evolução significativa tanto na parte de hardware quanto em software e isso garantiu não somente a realização de chamadas e envio de mensagens, como também o desenvolvimento de aplicativos com uma série de opções de serviços, funcionalidades e recursos para todos os usuários.

Diante disso é possível constatar que um aplicativo realmente pode fazer a diferença na hora de se conquistar os consumidores justamente por todas as funções que podem ser oferecidas para que o cliente possa fazer sua compra ou acessar o serviço oferecido sem ter que se preocupar com filas e outros imprevistos que ocorrem em compras físicas.

Rowles (2019) indica que primeiramente é preciso entregar valor para depois engajar sua audiência. E esse valor pode ser através de entretenimento ou até 
mesmo educação, o importante é oferecer um incentivo para os clientes se engajarem.

Quando um aplicativo possui uma interface intuitiva e apresenta ferramentas únicas para o usuário, este se sente ainda mais à vontade para utilizá-lo e aumentar seu engajamento com a empresa, fornecendo Feedback ou utilizando todas as funções do aplicativo como por exemplo: acesso à novos conteúdos disponibilizados pela empresa, acesso à serviços, promoções e outros benefícios que a companhia pode oferecer ao consumidor por meio de sua plataforma digital.

\subsubsection{CRM}

O CRM refere-se à administração da relação com o cliente, é a gestão minuciosa dos dados acerca de cada cliente com a finalidade de potencializar a sua fidelidade. Através da utilização eficaz desses dados pessoais, o CRM possibilita à empresa a elaboração de estratégias mais personalizadas e específicas para cada público, fazendo com que a organização se aproxime mais do cliente por meio de programas, anúncios, promoções ou serviços (KOTLER e ARMSTRONG, 2015).

O CRM pode ser utilizado como uma metodologia, estratégia ou ferramenta tecnológica, que viabiliza às organizações o gerenciamento de forma eficiente e eficaz das relações com seus clientes. Mais do que uma ferramenta de coleta de dados, o CRM propicia a elaboração de uma estratégia específica e individual, moldada para cada cliente, o que facilita e torna possível o processo de fidelização.

O processo de conversão de clientes em verdadeiros defensores da marca engloba uma série de processos relacionados ao envolvimento do consumidor com a empresa. Nessa era digital, o CRM é uma das técnicas utilizadas para intensificar esse engajamento pois trata-se do gerenciamento do relacionamento entre a organização e o cliente para gerar uma maior comunicação e consequentemente propiciar soluções (KOTLER; KARTAJAYA e SETIAWAN, 2017).

RC: 99341

Disponível em: https://www.nucleodoconhecimento.com.br/administracao/programade-fidelizacao 


\subsubsection{W2H}

Resolvendo de forma útil e versátil as diversas demandas no ambiente empresarial, a ferramenta $5 \mathrm{~W} 2 \mathrm{H}$ atua por meio das respostas de sete questões, visando chegar em um plano ação com base nos objetivos de uma organização. A sigla faz referências às questões que compõem esse método, que são: what (o que deve ser feito?); why (por que deve ser feito?); who (quem deve fazer?); where (onde será implementado?); when (quando será feito?); how (como será feito?) e how much (quanto custará toda a ação?).

Guerreiro (2012) cita que essa é uma ferramenta de análise que visa direcionar a discussão a um foco único, evitando a dispersão de ideias. Mesmo não sendo uma ferramenta completa na elaboração de planos de ação, ela pode ser combinada com outras, como por exemplo, com o ciclo PDCA.

Por conta do foco que é adquirido quando se usa essa forma de planejamento, o alcance dos objetivos almejados com as mudanças que precisam ser feitas se torna mais fácil e garante que as alterações sejam eficazes, já que foram planejadas sem perder o foco no que realmente é necessitado pela empresa.

De acordo com Seleme e Stadler (2012), para que a utilização dessa ferramenta garanta os resultados esperados, o analista deve conhecer bem todas as etapas que estão sendo estudadas para tornar a análise ainda mais eficaz.

Em vista disso, ao utilizar essa ferramenta a empresa deve garantir que os envolvidos entendam bem o objetivo das mudanças e como elas podem ser aplicadas para que o objetivo seja realmente alcançado. A equipe deve estudar e analisar bastante todas as possibilidades e só aí executar o plano de ação para que ele realmente seja eficaz.

RC: 99341

Disponível em: https://www.nucleodoconhecimento.com.br/administracao/programade-fidelizacao 


\section{MATERIAIS E MÉTODOS}

A metodologia pode ser descrita como a área que estuda os métodos utilizados para encontrar determinados conhecimentos. Há uma variedade de tipos de métodos que são aplicados de acordo com as exigências, em conformidade com o tema e os fins da pesquisa. Realizar uma pesquisa através de métodos não significa que apenas um padrão está sendo replicado, mas sim, que essa busca por informações está gerando e incentivando habilidades analíticas e ponderadoras que colaboram com o aperfeiçoamento da sociedade (ARAGÃO E MENDES NETA, 2017).

Considerando que a metodologia se trata da maneira pela qual um conhecimento pode ser formado, conclui-se que ela segue um trajeto específico, e com uma certa ordem e disciplina, cumpre os procedimentos estabelecidos (BASTOS E FERREIRA, 2016).

Deste modo, este trabalho utilizou-se de variadas ferramentas e métodos que permitiram a constatação de recursos para encontrar as soluções mais propícias para as adversidades identificadas na empresa Cinépolis.

\subsection{PROCEDIMENTOS METODOLÓGICOS}

Concerne aos métodos e técnicas utilizados para o colhimento de dados visando atingir os propósitos da pesquisa. A metodologia pode diversificar-se de acordo com o modelo de pesquisa adotado, a área do conhecimento escolhida e o assunto que será abordado no conteúdo do trabalho (LIBÓRIO E TERRA, 2015).

O método pode ser definido como o caminho utilizado para alcançar determinado objetivo e ao possuir este caminho, se torna mais fácil a realização do trajeto tendo a consciência da sua posição atual e onde se pretende chegar e como efetuá-lo (PEREIRA et al, 2018).

RC: 99341

Disponível em: https://www.nucleodoconhecimento.com.br/administracao/programade-fidelizacao 
Assim sendo, este trabalho sucedeu-se mediante a apuração de dados e o processamento de informações, objetivando a elaboração de técnicas e estratégias para auxiliar o cinema no alcance e fidelização de clientes.

\subsubsection{QUANTO À NATUREZA}

A classificação de pesquisas dá-se por meio de dois tipos. O primeiro é definido como a pesquisa básica, onde são abordados estudos que visam contribuir com conhecimentos fundamentais. O segundo tipo é intitulado como pesquisa aplicada, que envolve estudos cujo propósito é solucionar problemas encontrados na esfera da sociedade (GIL, 2017).

A utilização de métodos mistos, por sua vez, estimula os métodos a partilharem dos mesmos conteúdos do trabalho e a pesquisarem informações adicionais que se integralizem. Este método proporciona aos pesquisadores uma sequência de dados mais abundantes do que obteriam fazendo o uso de apenas um único método (YIN, 2015).

Neste projeto, a natureza adotada foi a pesquisa aplicada pois esta fornece conhecimentos que podem ser utilizados na empresa. A abordagem utilizada foi a mista ou quali-quantitativa, tendo em vista que dados quantitativos foram colhidos e informações qualitativas foram obtidas e analisadas por meio de questionários e entrevistas, permitindo o desenvolvimento das questões da pesquisa de forma mais detalhada e completa.

\subsubsection{QUANTO AOS FINS}

O objetivo trata-se do alvo a ser almejado durante toda a produção da pesquisa (PEREIRA et al., 2018).

Referindo-se aos objetivos, há três categorias de pesquisas. A exploratória que tem como intuito aumentar o conhecimento sobre certo acontecimento; a descritiva que busca compreender e esclarecer determinada situação estudada, em conjunto com

RC: 99341

Disponível em: https://www.nucleodoconhecimento.com.br/administracao/programade-fidelizacao 
as suas particularidades e adversidades; e a explicativa que está focada na tarefa de detectar as causas que determinaram ou colaboraram com a ocorrência de um fenômeno, a sua finalidade é elucidar o motivo pelo qual um fato social ou natural ocorre (ZANELLA, 2013).

Considera-se esta pesquisa como exploratória pois buscou-se à amplificação do conhecimento acerca dos fenômenos ocorridos na empresa estudada, e descritiva, pois identificou e retratou as características e problemas da organização.

\subsubsection{QUANTO AOS MEIOS}

Os meios através dos quais obtém-se as informações que originarão as soluções para o problema presente na pesquisa, excetuando a pesquisa bibliográfica, são intitulados como instrumentos de coleta de dados. Os instrumentos mais comumente utilizados são os documentos, as entrevistas, os questionários, entre outros (BASTOS E FERREIRA, 2016).

A definição dos meios utilizados para a obtenção e análise das informações originase das adversidades específicas da pesquisa e das suas finalidades (ZANELLA, 2013).

Quanto aos meios, este projeto fez o uso da pesquisa bibliográfica tencionando o aprimoramento e enriquecimento do artigo com conteúdo científico. Utilizou-se também a aplicação de questionários como método para o levantamento de informações específicas da organização.

\subsection{CARACTERÍSTICAS DA EMPRESA}

Considerada a primeira unidade inaugurada no Estado do Amazonas, o complexo da Cinépolis localizado em Manaus - AM, no Shopping Ponta Negra, na Avenida Coronel Teixeira, iniciou as suas atividades no dia 8 de agosto de 2013. A organização opera com produtos e serviços, exibindo produções cinematográficas,

RC: 99341

Disponível em: https://www.nucleodoconhecimento.com.br/administracao/programade-fidelizacao 
vendendo alimentos e bebidas e fornecendo as suas salas de cinema para a realização de eventos festivos e corporativos por meio de aluguel.

\section{RESULTADOS E DISCUSSÕES}

Através do Diagnóstico Organizacional executado na empresa Cinépolis Operadora de Cinemas do Brasil LTDA, adquiriu-se informações por intermédio de pesquisas e entrevistas. Após a análise dos dados, definiu-se os pontos fortes e fracos das áreas funcionais da organização e obteve-se uma média, conforme mostra o Gráfico 01: Desempenho por Área Funcional a seguir:

Gráfico 01: Desempenho por área funcional.

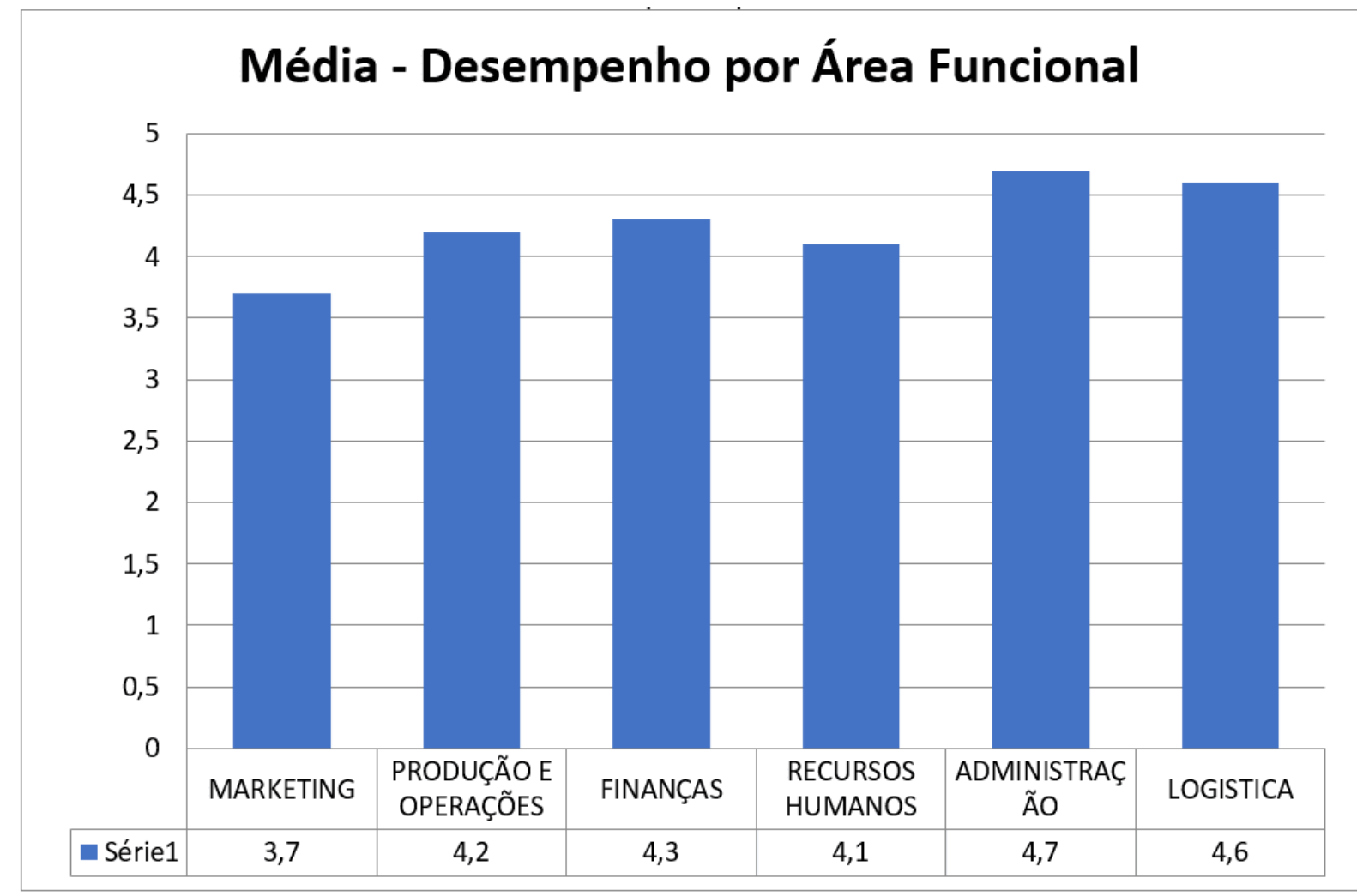

Fonte: Elaborado pela equipe com base nos dados fornecidos pela Cinépolis, 2021.

O gráfico foi elaborado com base nas informações obtidas por meio de questionários que foram respondidos pela gerente da organização. Cada área funcional foi analisada através de 10 quesitos específicos de cada departamento, estes recebiam

RC: 99341

Disponível em: https://www.nucleodoconhecimento.com.br/administracao/programade-fidelizacao 
uma pontuação entre 1,0 ponto, que equivalia à um ponto muito fraco, e 5,0 pontos, que correspondia à um ponto muito forte. Por conseguinte, a soma da pontuação de cada área gerou uma média que viabilizou a definição da área com a menor nota, ou seja, a área mais crítica da empresa.

Percebe-se que a área da administração e logística foram classificadas como as de maior desempenho, enquanto as áreas de finanças, produção e operações e recursos humanos foram consideradas áreas de desempenho mediano. O marketing foi identificado como a área funcional mais crítica da organização.

Quadro 01: Área mais crítica da organização.

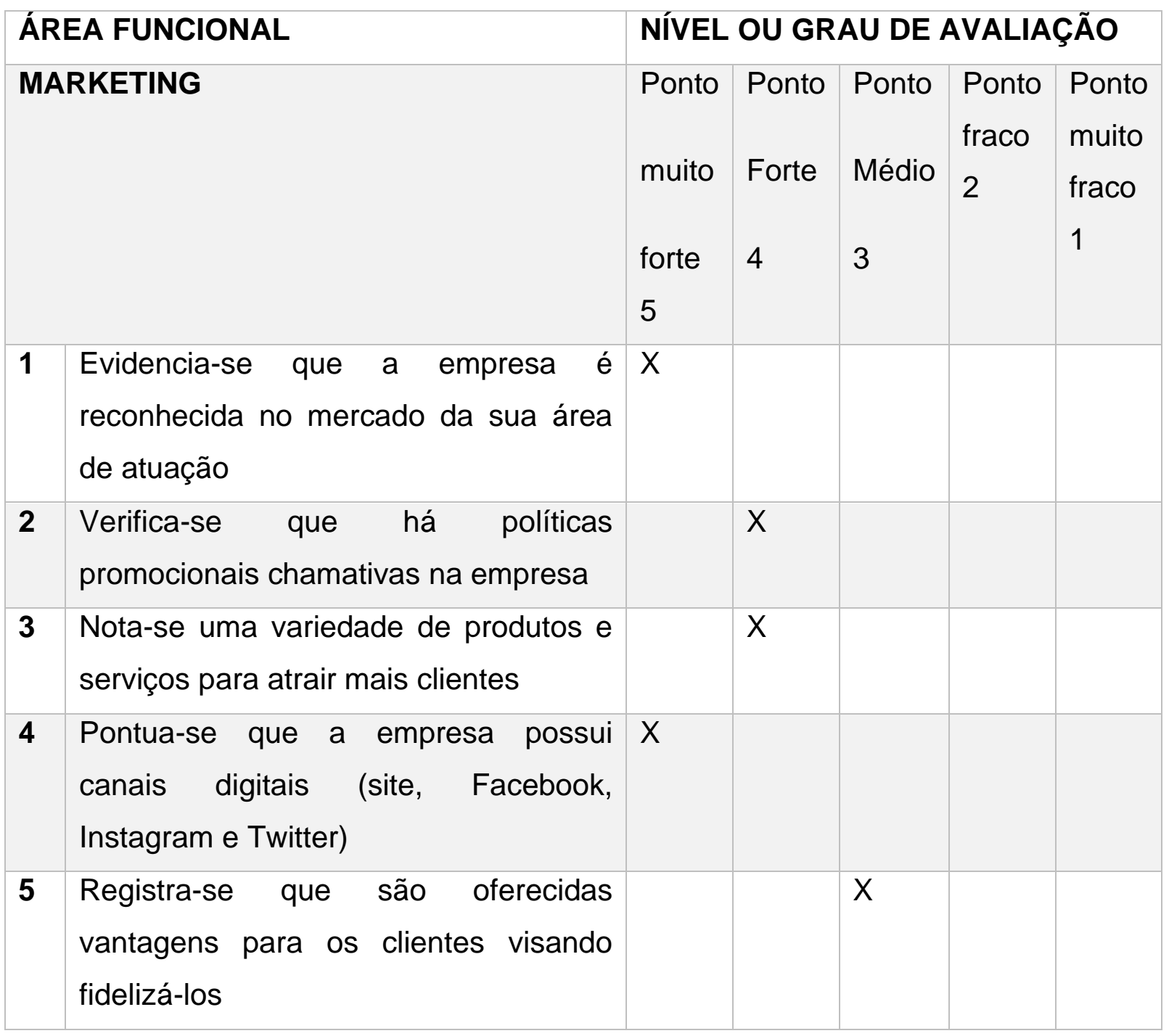

RC: 99341

Disponível em: https://www.nucleodoconhecimento.com.br/administracao/programade-fidelizacao 


\begin{tabular}{|c|c|c|c|c|c|c|}
\hline 6 & $\begin{array}{l}\text { Observa-se que a organização possui } \\
\text { produtos exclusivos que a diferenciam } \\
\text { da concorrência }\end{array}$ & & $X$ & & & \\
\hline 7 & $\begin{array}{l}\text { Aponta-se } 0 \quad \text { investimento em } \\
\text { tecnologias exclusivas como diferencial } \\
\text { competitivo }\end{array}$ & $x$ & & & & \\
\hline 8 & $\begin{array}{l}\text { Constata-se a existência de estratégias } \\
\text { de marketing para compensar a queda } \\
\text { de vendas }\end{array}$ & & & & $x$ & \\
\hline 9 & $\begin{array}{l}\text { Percebe-se o uso dos canais digitais } \\
\text { de forma eficiente para divulgar } \\
\text { produtos, serviços e promoções }\end{array}$ & & & $\mathrm{X}$ & & \\
\hline 10 & $\begin{array}{l}\text { Salienta-se que a empresa possui } \\
\text { estratégias para atrair novos clientes }\end{array}$ & & & & $\mathrm{x}$ & \\
\hline \multicolumn{2}{|r|}{ TOTAL $(\Sigma)$} & 15 & 12 & 6 & 4 & 0 \\
\hline \multicolumn{2}{|r|}{ MÉDIA POR GRAU (POR COLUNA) } & 1,5 & 1,2 & 0,6 & 0,4 & 0 \\
\hline \multicolumn{2}{|r|}{ 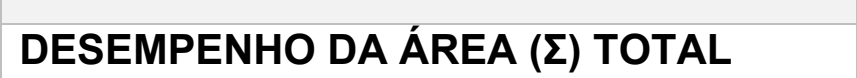 } & 3,7 & & & & \\
\hline
\end{tabular}

Fonte: Elaborado pela equipe com base nos dados fornecidos pela Cinépolis, 2021.

Ao analisar os quesitos da área do marketing no Quadro 01, evidencia-se que o item 8, que trata da existência de estratégias de marketing para a compensação da queda de vendas, e o item 10, que versa sobre as estratégias para a captação de novos clientes, foram considerados os itens mais fracos da área. $O$ item 5 , que se refere às vantagens oferecidas aos clientes visando a fidelização, e o item 9 , relacionado ao uso dos canais digitais de forma eficiente, foram apontados como pontos medianos. Sendo esses, portanto, os itens com a menor pontuação da área do marketing, que levaram à definição da seguinte pergunta problema: Como a implementação do marketing de relacionamento pode coadjuvar na fidelização de clientes e no alcance de outros novos? 


\subsection{PROPOSTA DE SOLUÇÃO}

Visando a solução do problema detectado no marketing, área mais crítica da Cinépolis, foram elaboradas propostas para o aprimoramento do departamento na empresa.

O marketing se mostra uma área de abordagem indispensável, em adição à geração de valor, uma vez que também evidencia o vínculo existente entre o cliente e a empresa. É de responsabilidade da área trabalhar tendo em vista a obtenção de novos clientes e a fidelização do público atual, utilizando-se de estratégias de atração e retenção, por exemplo.

Visto que os principais problemas identificados na área do marketing da Cinépolis estão relacionados ao uso de estratégias, fidelização de clientes e uso eficiente das plataformas digitais, as seguintes propostas foram elaboradas com o intuito de solucionar tais adversidades.

Quadro 02: Proposta de Solução.

\begin{tabular}{|l|l|l|l|l|}
\hline Itens & Ações Interventivas & Cronologia & Duração & Custo \\
\hline $\mathbf{1}$ & $\begin{array}{l}\text { Reformular o atual plano de } \\
\text { fidelização da empresa }\end{array}$ & Novembro/2021 & 50 dias & $\mathrm{R} \$ 10.000,00$ \\
\hline $\mathbf{2}$ & $\begin{array}{l}\text { Criar benefícios exclusivos para } \\
\text { membros do novo clube }\end{array}$ & Novembro/2021 & 30 dias & $\mathrm{R} \$ 8.000,00$ \\
\hline $\mathbf{3}$ & $\begin{array}{l}\text { Executar a divulgação do clube } \\
\text { de fidelização }\end{array}$ & Janeiro/2022 & Mensal & $\mathrm{R} \$ 5.000,00$ \\
\hline $\mathbf{4}$ & $\begin{array}{l}\text { Reestruturar o aplicativo da } \\
\text { empresa }\end{array}$ & Dezembro/2021 & 60 dias & $\mathrm{R} \$ 20.000,00$ \\
\hline
\end{tabular}

Fonte: Elaborado pelos autores, 2021.

Deste modo, as propostas foram formuladas objetivando o alcance e a fidelização de clientes por meio de um novo plano de fidelização mais atrativo, complementado 
com benefícios exclusivos, como descontos especiais semanais e em datas comemorativas, acúmulo de pontos para trocar por brindes, carteirinhas personalizadas com temáticas de filmes, entre outros. Tudo isso visando a criação de um vínculo emocional para que o cliente se sinta mais próximo e fiel a empresa, fazendo com que esta seja sempre a sua primeira opção. Além disso, há também o aprimoramento do aplicativo da empresa para que ele se torne mais interativo e vantajoso.

Tais objetivos foram desenvolvidos levando em conta alguns dos princípios do CRM que visa a centralização no cliente através de estratégias e de atrativos para eles. Dessa forma, será possível compreender melhor o consumidor e assim desenvolver métodos de vendas mais eficientes e eficazes, sempre visando a captação de novos públicos. Além de todos esses fatores, há também a melhora do relacionamento cliente e empresa, desenvolvendo um ambiente ideal para manter essa relação por muito tempo.

A ferramenta $5 \mathrm{WH} 2$ será utilizada para a estruturação das ações interventivas, nela as atividades, prazos e responsabilidades serão detalhados para um maior controle da ação, definindo especificidades como: o que irá ser feito? por que será feito? onde? quem irá fazer? quando? como? E quanto irá custar?

\subsubsection{REFORMULAR O ATUAL PLANO DE FIDELIZAÇÃO DA EMPRESA}

Atualmente a Cinépolis possui um plano de fidelização chamado "Clube de Vantagens", porém esse plano é pouco atrativo, possui descontos para sessões especiais com restrições de horário e períodos de férias e não contém uma grande variedade de promoções, elas são as mesmas para apenas três dias da semana e isso acaba por se tornar rotineiro, perdendo a promessa de uma vantagem exclusiva que faça valer a pena se cadastrar no clube.

RC: 99341

Disponível em: https://www.nucleodoconhecimento.com.br/administracao/programade-fidelizacao 
A premissa do plano de fidelização é a de que além de premiar e bonificar os clientes mais assíduos por meio de atrativos especiais, visa-se atrair para visitas mais frequentes os clientes que não são tão ativos assim, objetivando sempre tornar a empresa a primeira opção de todos.

Quadro 03: 5W2H - Reformular o atual plano de fidelização da empresa.

\section{Reformular o atual plano de fidelização da empresa}

O que? Refazer o plano de fidelização da empresa para oferecer novos benefícios e vantagens para os clientes.

Por quê? Para atrair novos clientes, fazer com que frequentem mais vezes a empresa e gratificar os consumidores regulares.

Onde? Na Cinépolis.

Quando? Novembro de 2021.

Quem? Equipe especializada em marketing.

Como? Realizar reuniões para a elaboração de novas propostas de planos.

Quanto? R $\$ 10.000,00$

Fonte: Elaborado pelos autores, 2021.

O quadro acima detalha as informações sobre a execução da primeira ação interventiva que se trata da reformulação do atual plano de fidelização da Cinépolis. Nesta fase, a empresa irá contratar uma equipe especializada em marketing de relacionamento para que reuniões sejam feitas, considerando aspectos atrativos para a elaboração de um novo programa através de pesquisas. As reuniões serão realizadas na empresa, iniciarão no mês de novembro de 2021 e terão a duração de 50 dias.

RC: 99341

Disponível em: https://www.nucleodoconhecimento.com.br/administracao/programade-fidelizacao 


\subsubsection{CRIAR BENEFÍCIOS EXCLUSIVOS PARA MEMBROS DO NOVO CLUBE}

Para que o novo plano seja atrativo e vantajoso a ponto de despertar o interesse de participar dos clientes, ele precisa possuir benefícios exclusivos bem elaborados como o desenvolvimento constante de novas promoções semanais e em datas comemorativas, acúmulo de pontos para trocar por brindes e a criação de uma carteirinha personalizada com temáticas de filmes por exemplo.

Quadro 04: 5W2H - Criar benefícios exclusivos para membros do novo clube.

\section{Criar benefícios exclusivos para membros do novo clube}

O que? Elaborar vantagens exclusivas para os clientes cadastrados no plano de fidelização da empresa.

Por quê? Para criar um vínculo com o cliente e garantir que ele volte com frequência.

Onde? Na Cinépolis.

Quando? Novembro de 2021.

Quem? Equipe da área do marketing.

Como? Através de reuniões para a escolha dos benefícios.

Quanto? R\$8.000,00

Fonte: Elaborado pelos autores, 2021.

O quadro acima especifica as informações referentes a criação dos benefícios exclusivos para os membros do clube de fidelização. O objetivo principal desta ação é garantir, através das estratégias das promoções e brindes, a frequência dos consumidores e criar um vínculo de lealdade entre a empresa e os clientes pois estes se sentem no dever de retribuir os privilégios e acabam dando preferência para a empresa que mais os cativam. As reuniões ocorrerão dentro da própria empresa e terão a duração de 30 dias, tendo início no mês de novembro de 2021. O custo foi definido com base no valor da contratação de uma equipe de marketing.

RC: 99341

Disponível em: https://www.nucleodoconhecimento.com.br/administracao/programade-fidelizacao 


\subsubsection{EXECUTAR A DIVULGAÇÃO DO CLUBE DE FIDELIZAÇÃO}

É indispensável a propagação do clube de fidelização para que muitas pessoas saibam da sua existência e se afiliem. Novos consumidores também poderão ser atraídos pelos benefícios exclusivos oferecidos. Quanto mais clientes aderirem ao programa, mais dados de padrões de consumo a empresa irá ter e dessa forma, poderá se adaptar aos públicos-alvo e elaborar estratégias específicas para eles.

Quadro 05: 5W2H - Executar a divulgação do clube de fidelização.

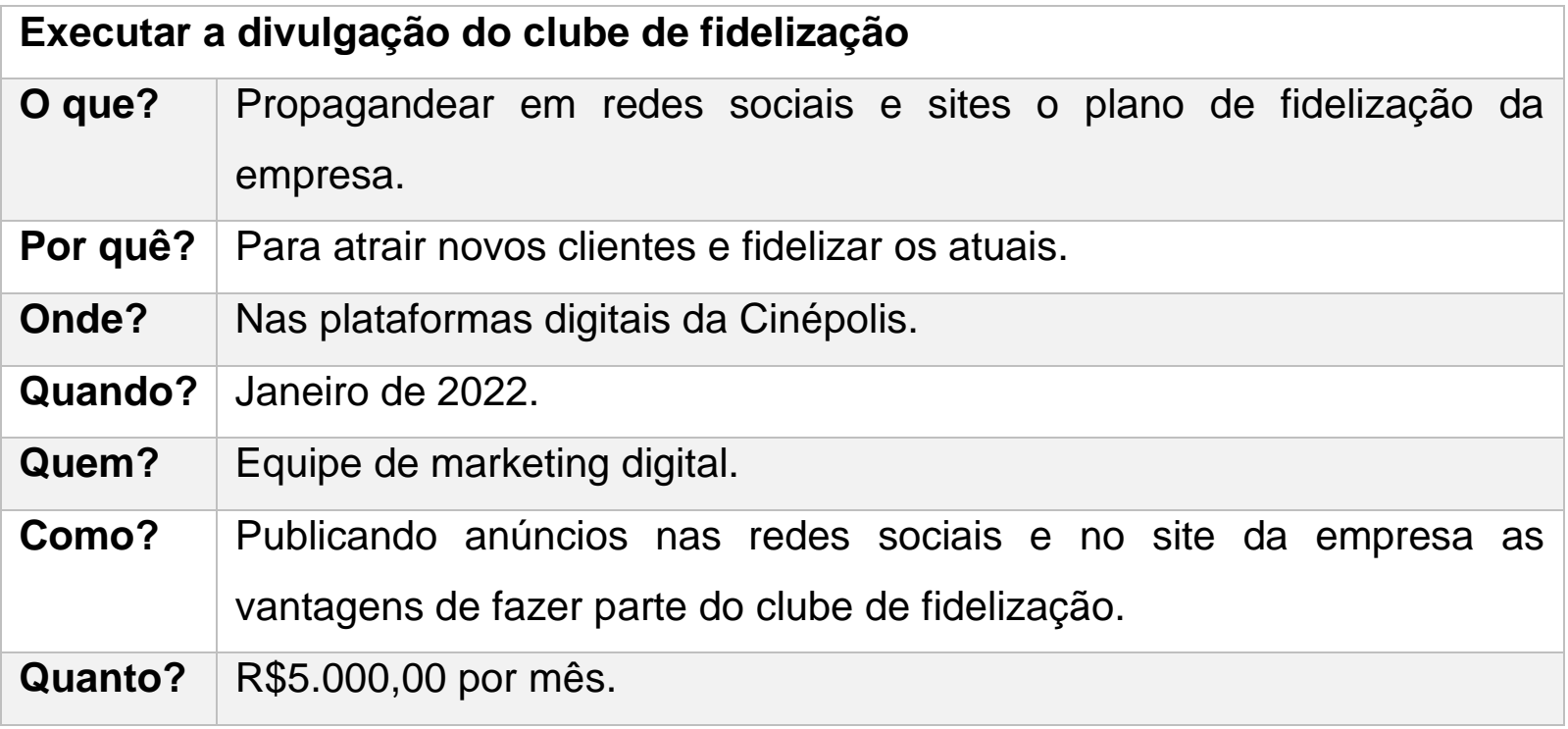

Fonte: Elaborado pelos autores, 2021.

O quadro acima minucia os dados relacionados à divulgação do plano de fidelização da empresa. Espera-se atrair membros para que ocorra o processo de fidelização, tanto de novos quanto de atuais clientes. As propagandas sobre o clube e as vantagens serão feitas nas mídias sociais da empresa como o Twitter, Facebook, Instagram e site, tendo em vista o alcance do maior número de pessoas possível. $O$ início da divulgação está previsto para o mês de janeiro de 2022. Ela será feita mensalmente e terá o custo da contratação de um profissional de marketing digital de $\mathrm{R} \$ 5.000,00$.

RC: 99341

Disponível em: https://www.nucleodoconhecimento.com.br/administracao/programade-fidelizacao 


\subsubsection{REESTRUTURAR O APLICATIVO DA EMPRESA}

A reestruturação do aplicativo é uma ação de grande importância, ela visa aproximar o cliente ainda mais através da plataforma digital da empresa com o uso de uma nova interface mais intuitiva e com mais funcionalidades para os usuários. Tal modificação tornará ainda mais simples a obtenção de informações sobre filmes, promoções, horários e valores de cada sessão, benefícios disponíveis para o consumidor e acesso a outros serviços como o aluguel de salas para reuniões ou para datas comemorativas.

Quadro 06: 5W2H - Reestruturação do aplicativo da empresa.

\section{Reestruturação do aplicativo da empresa}

O que? Alteração do software da Cinépolis para dispositivos eletrônicos móveis.

Por quê? Para facilitar o acesso do cliente aos serviços da empresa.

Onde? Na plataforma digital da Cinépolis.

Quando? Dezembro de 2021.

Quem? Desenvolvedor de aplicativos.

Como? Adicionando novas funções no aplicativo para que este se torne mais útil e prático.

Quanto? $\mathrm{R} \$ 20.000,00$.

Fonte: Elaborado pelos autores, 2021.

O quadro acima informa detalhes sobre a reestruturação do aplicativo da empresa. O objetivo principal é justamente manter todas as funções e serviços da empresa em um mesmo local para que o interessado possa comprar seus ingressos, alugar salas para dias específicos e até mesmo resgatar seus benefícios sem precisar sair de casa, o cliente poderá se programar para um dia que queira ver um filme sem se preocupar com filas ou esperas antes de entrar em sua sessão.

RC: 99341

Disponível em: https://www.nucleodoconhecimento.com.br/administracao/programade-fidelizacao 
Além disso, os consumidores poderão ser capazes de interagir ainda mais com a companhia auxiliando na melhoria dos serviços oferecidos por ela. Ao assistir algum filme e utilizar algum serviço o cliente pode comentar e dar seu feedback a respeito do que foi ofertado, avaliando o filme ou serviço e deixando opiniões e sugestões para a melhora do que foi consumido. A ação custará $R \$ 20.000,00$ e será realizada no mês de dezembro de 2021, a empresa precisará contratar um desenvolvedor de aplicativos.

\section{CONSIDERAÇÕES FINAIS}

O número de empresas trabalhando no mesmo ramo de atuação, oferecendo os mesmos produtos e serviços, vive em constante crescimento. Para lidar com esse fato, os gestores precisam traçar estratégias e utilizarem-se de metodologias que garantam uma boa participação de mercado para as suas organizações. Diante disso, a manutenção do relacionamento com os clientes para fazer com que estes se tornem consumidores fiéis e verdadeiros defensores da marca, transforma-se em uma estratégia que pode impulsionar o crescimento da organização e garantir sua presença no mercado.

Na primeira etapa deste trabalho, através do diagnóstico organizacional realizado na Cinépolis, constatou-se que o marketing era a área mais crítica da empresa. A partir dos pontos mais fracos da área, estabeleceu-se como pergunta problema: "como a implementação do marketing de relacionamento pode coadjuvar na fidelização de clientes e no alcance de outros novos?". Esta pergunta norteou a construção deste estudo que mostrou através de pesquisas que as estratégias alicerçadas no marketing de relacionamento fazem com que os clientes se sintam mais próximos da organização, em um vínculo de prioridade de ambos os lados e que resulta na fidelização e consequentemente acaba atraindo novos consumidores, tanto por meio dos próprios defensores da marca quanto por conta das vantagens oferecidas pela empresa.

RC: 99341

Disponível em: https://www.nucleodoconhecimento.com.br/administracao/programade-fidelizacao 
$\mathrm{Na}$ segunda etapa, foram abordadas as propostas de solução visando atingir o objetivo geral e os objetivos específicos deste trabalho que consistiam em demonstrar os possíveis benefícios que a empresa poderá obter caso venha a implementar as soluções sugeridas. As propostas de instalação de um novo plano de fidelização e da reestruturação do aplicativo da operadora de cinemas, tiveram como base os princípios do marketing de relacionamento e os preceitos do CRM e mediante as suas implantações, espera-se que a empresa obtenha vantagens como a fidelização dos clientes e o alcance de novos consumidores.

Por fim, as propostas de solução desenvolvidas nessa pesquisa com o auxílio da ferramenta $5 \mathrm{~W} 2 \mathrm{H}$, supriram os objetivos incialmente estabelecidos e podem ser de extrema importância para futuras pesquisas que venham a ser realizadas sobre os temas relacionados com o conteúdo que foi apresentado neste trabalho.

\section{REFERÊNCIAS}

ARAGÃO, José Wellington Marinho de; MENDES NETA, Maria Adelina Hayne. Metodologia científica. Salvador: UFBA, Faculdade de Educação, Superintendência de Educação a Distância, 2017.

BARCELLOS, Ricardo; SCHELELA, Simone Schuster. Marketing e vendas. Paraná: Instituto Federal de Educação, Ciência e Tecnologia, 2012.

BASTOS, Maria Clotilde Pires; FERREIRA, Daniela Vitor. Metodologia científica. Londrina: Editora e Distribuidora Educacional S.A., 2016.

CARVALHO, Luis Osete Ribeiro, et al. Metodologia científica: teoria e aplicação na educação a distância. Petrolila-PE: Fundação Universidade Federal do Vale do São Francisco, 2019.

GIL, Antonio Carlos. Como elaborar projetos de pesquisa. 6. ed. São Paulo: Atlas, 2017.

RC: 99341

Disponível em: https://www.nucleodoconhecimento.com.br/administracao/programade-fidelizacao 
GUERREIRO, Karen Menger da Silva. Gestão de qualidade. Curitiba-PR: E-TEC, 2012.

KOTLER, Philip; KARTAJAYA, Hermawan; SETIAWAN, Iwan. Marketing 4.0 do tradicional ao digital. Rio de Janeiro: Editora Sextante, 2017.

KOTLER, Philip; KELLER, Kevin Lane. Administração de marketing. 15. ed. São Paulo: Pearson Education do Brasil, 2018.

KOTLER; Philip; ARMSTRONG, Gary. Princípios de marketing. 15. ed. São Paulo: Pearson Education do Brasil, 2015.

LIBÓRIO, Daisy; TERRA, Lucimara. Metodologia científica. São Paulo: Rede Internacional de Universidades Laureate, 2015.

OLIVEIRA, Tatiana Souto Maior de. Marketing digital e novas mídias. 1. ed. Curitiba: IESDE Brasil S.A., 2018.

PEREIRA, Adriana Soares, et al. Metodologia da pesquisa científica. 1. ed. Santa Maria: UFSM, NTE, 2018.

ROWLES, Daniel. Digital Branding: Estratégias, táticas e ferramentas para impulsionar o seu negócio na era digital. 1. ed. São Paulo: Autêntica Business, 2019.

SELEME, Robson; STADLER, Humberto. Controle de qualidade: as ferramentas essenciais. 2. ed. Curitiba: ibpex, 2012.

SILVA, Marcelo Moro da; SANTOS, Marilde Terezinha Prado. Os Paradigmas de Desenvolvimento de Aplicativos para Aparelhos Celulares. Revista TIS, São CarlosSP, v. 3, n. 2, p. 162-170, mai./ago. 2014. Disponível em: http://www.revistatis.dc.ufscar.br/index.php/revista/article/download/86/80. Acesso em: 02 de abril de 2021. 
YIN, Robert K. Estudo de caso: planejamento e métodos. 5. ed. Porto Alegre: Bookman, 2015.

ZANELLA, Liane Carly Hermes. Metodologia de pesquisa. 2. ed. Florianópolis: Departamento de Ciências da Administração/UFSC, 2013.

Enviado: Outubro, 2021.

Aprovado: Outubro, 2021. 